\title{
Research on Strip Filling Surface Subsidence Rule
}

\author{
SHI Yongkui ${ }^{1,2}$, QI Minhua ${ }^{2}$, ZHANG Jingyu ${ }^{2}$,HAO Jian ${ }^{1,2}$ \\ (1.State Key Laboratory of Mine Disaster Prevention and Control, Shandong \\ University of Science and Technology, Qingdao 266590 2. College of Resources and \\ Environmental Engineering, Shandong University of Science and Technology \\ Qingdao 266590)
}

\begin{abstract}
For recycling the remaining coal pillars resources in strip mining, a repeated mining method of using the strip filling replacement of strip coal pillar is proposed, a technical principle of strip filling controlling surface subsidence is illustrated, and the main filling factors which influence the surface subsidence rule are analyzed, FLAC3D is used to analyze the sensitivity of the surface subsidence on the filling parameters (width and strength), the results show that as a "bridge pier", the strip filling body supports the overburden strata and achieve the purpose of controlling the movement of overburden strata through controlling the movement of the overlying bearing stratum; rules of surface subsidence (vertical subsidence, gradient of slope, curvature and horizontal distortion) would decrease as filling parameters (width and strength)increase; the influence of filling parameters (width and strength) on the surface subsidence (vertical subsidence, gradient of slope, curvature and horizontal distortion) is diminishing marginal.
\end{abstract}

Keywords: Filling mining; Strength; The surface deformation; Filling parameters

\section{Introduction}

As an important technology, strip mining solves "under buildings, railways, and water bodies" mining of coal seam through the method of recovering part of the coal pillar and reserving part of the coal pillar to achieve the purpose of controlling surface movement and deformation. Its disadvantage is that the coal extraction rate is low, generally less than $50 \%$ [1-3]. The leaving coal pillar of strip mining is a huge resource loss, and if the repeated mining is not carried out, it will seriously threat the length of service, and will also not meet the requirement of the sustainable development of China. In theory, the strip filling mining technology is used to mix filling aggregate and stone material which from solid waste such as coal gangue etc. The high strength of filling material is produced to fill the down hole, which could achieve the purpose of replacement down hole coal resources. But the recoverable resources rate and filling cost tolerance of strip coal pillar are less than intact coal, and therefore, it was impossible to use the technical proposal of full filling the mined-out area[3-7]. For cementation filling of metal mine, the filling cost accounted for $35 \% \sim 50 \%$ of the direct cost of mining, such as the Jinchuan 
nickel mine cemented filling cost up to $84 \sim 100$ yuan $/ \mathrm{m}^{3}[1]$. At present, the increased tons of coal mine full filling cost is estimated around $50 \mathrm{RMB} / \mathrm{t}$ or even higher. Using mining scheme of partial stowage in mined-out area, that is, the filling range was only one part of the mined-out area, which could effectively reduce the filling cost and control the movement of overburden strata, and is an important method to realize repeated mining of strip pillar.

The thesis illuminates the technology principle of the strip filling mining controlling surface subsidence, and using FLAC3D numerical simulation on the surface subsidence on the sensitivity of the filling parameters (width and strength) to provide theoretical support for the application of strip mining filling.

\section{The dominant mechanism of strip} filling controlling surface subsidence Strip filling as an important method to control the surface subsidence which the essence was using the supporting role of stripe filling body on overburden hard rock strata to achieve the purpose of controlling the rock strata. In the strip filling, strip filling body played a role as "bridge pier", the weight of the overburden strata effect on coal seam when before mining, the weight of overburden strata transferred from coal seam to the filling body during the process of stripe filling, as long as reasonable design filling parameters which could guarantee the stability of bridge structure of "overburden strata-strip filling body" [6]. Designing filling parameters reasonably is the key to guarantee the strip filling. A hard stratum is generally chosen as "the supporting strata" by strip filling. Only when "the supporting strata" does not break and its movement rate is controlled that the overburden strata will keep stable. The choose of "the supporting strata" has a great relation with the structure of overburden strata in stope. In according with the location of "the supporting strata", it can be divided into two parts: immediate roof as "the supporting strata" as shown in the figure 1 , and the upper strata as "the supporting strata" as shown in the figure 2.

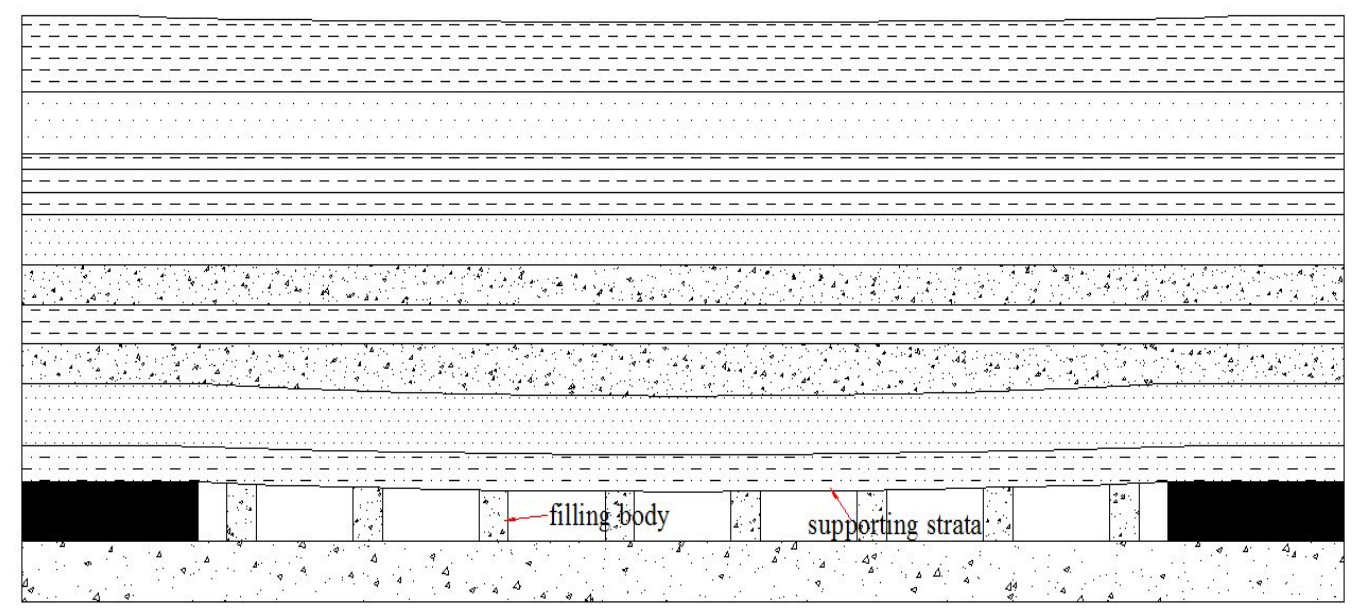

Fig.1 Immediate roof as the "supporting strata" 


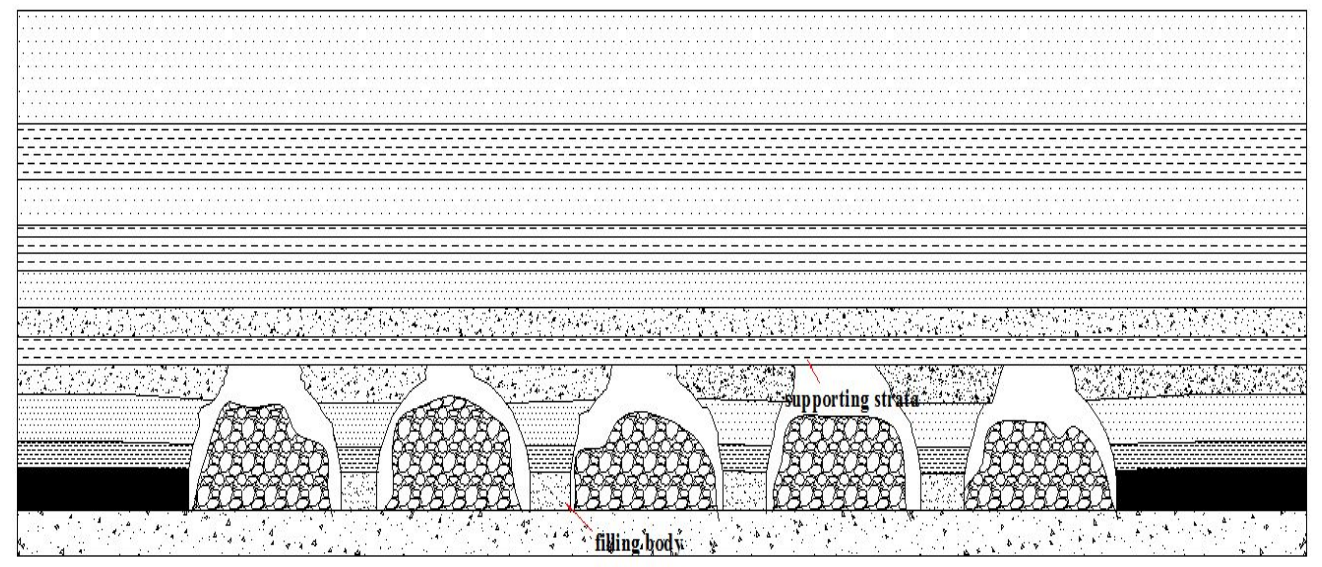

Fig.2 Upper strata "supporting strata"

3. The sensitivity analysis on the main influence factor of strip filling surface subsidence

As the surface subsidence is mainly influenced by the filling parameter, the paper has a detailed analysis that different filling strip width and filling body strength has an effect on the surface subsidence.

In this paper, FLAC3D model is planned to build to do numerical simulation on the strip filling surface subsidence rule, and the influence of filling body strength on the stability of strip filling surface is analyzed deeply and carefully.

Model size: The model is made of 23 strata, horizontal taking $160 \mathrm{~m}$, extension direction taking $120 \mathrm{~m}$, height taking $132 \mathrm{~m}$.

Material parameter: The model takes Jisuo coal mine as the realistic basis, in accordance with experience, taking material parameter table 1 .

Table 1 Rock mechanical parameter table

\begin{tabular}{ccccccc}
\hline Stratum Identifier & $\begin{array}{c}\text { Thickness } \\
(\mathrm{m})\end{array}$ & $\begin{array}{c}\text { Bulk } \\
\text { Modulus } \\
(\mathrm{GPa})\end{array}$ & $\begin{array}{c}\text { Shear } \\
\text { Modulus } \\
(\mathrm{GPa})\end{array}$ & $\begin{array}{c}\text { Angle of } \\
\text { Friction } \\
\left({ }^{0}\right)\end{array}$ & $\begin{array}{c}\text { Cohesive } \\
\text { Force } \\
(\mathrm{MPa})\end{array}$ & $\begin{array}{c}\text { Tensile } \\
\text { Strength } \\
(\mathrm{MPa})\end{array}$ \\
\hline Sandy Clay & 28 & 1 & 1 & 25 & 0.8 & 0.8 \\
Siltstone & 10 & 15.6 & 11 & 26 & 2.2 & 1.6 \\
Mudstone & 4 & 3.33 & 2.5 & 22 & 3.4 & 1.0 \\
Medium Sand & 4 & 11.6 & 8 & 26 & 1.8 & 1.2 \\
Limestone & 4 & 22.6 & 11.1 & 31 & 4.3 & 2.59 \\
Fine Sand Clay & 4 & 1 & 1 & 25 & 0.8 & 0.8 \\
Clunch & 7 & 1 & 1 & 25 & 0.8 & 0.8 \\
Fine Sandstone & 6 & 28 & 11 & 36 & 5.6 & 1.6 \\
Sandy Mudstone & 20 & 6 & 5 & 22 & 0.8 & 4 \\
Coal16 & 1 & 5 & 2.5 & 25 & 1.2 & 1.5 \\
Limestone & 4.5 & 22.6 & 11.1 & 31 & 4.3 & 2.59 \\
Obturator 8MPa & 1 & 0.7 & 1.0 & 20 & 1.0 & 0.5 \\
Obturator 10MPa & 1 & 1.0 & 1.5 & 22 & 1.0 & 0.8 \\
Obturator 12MPa & 1 & 1.5 & 2.0 & 25 & 1.2 & 1.0 \\
\hline
\end{tabular}




\subsection{The influence of filling strip width}

This part uses FLAC3D to simulate the filling strip width's impact on the surface subsidence rule, and the filling strip width takes $8 \mathrm{~m}, 10 \mathrm{~m}, 12 \mathrm{~m}$ respectively, working face length being $80 \mathrm{~m}$, its scope in the model being $\mathrm{y}=20 \mathrm{~m} \sim 100 \mathrm{~m}$, and the length of the mining being $120 \mathrm{~m}$, its scope in the model being $\mathrm{x}=20 \mathrm{~m} \sim 140 \mathrm{~m}$, the strength of filling body taking $10 \mathrm{MPa}$, the separation distance of the filling strip taking $10 \mathrm{~m}$. When the width of the filling strip is $10 \mathrm{~m}$, the surrounding rock movement is shown in the figure 3 .

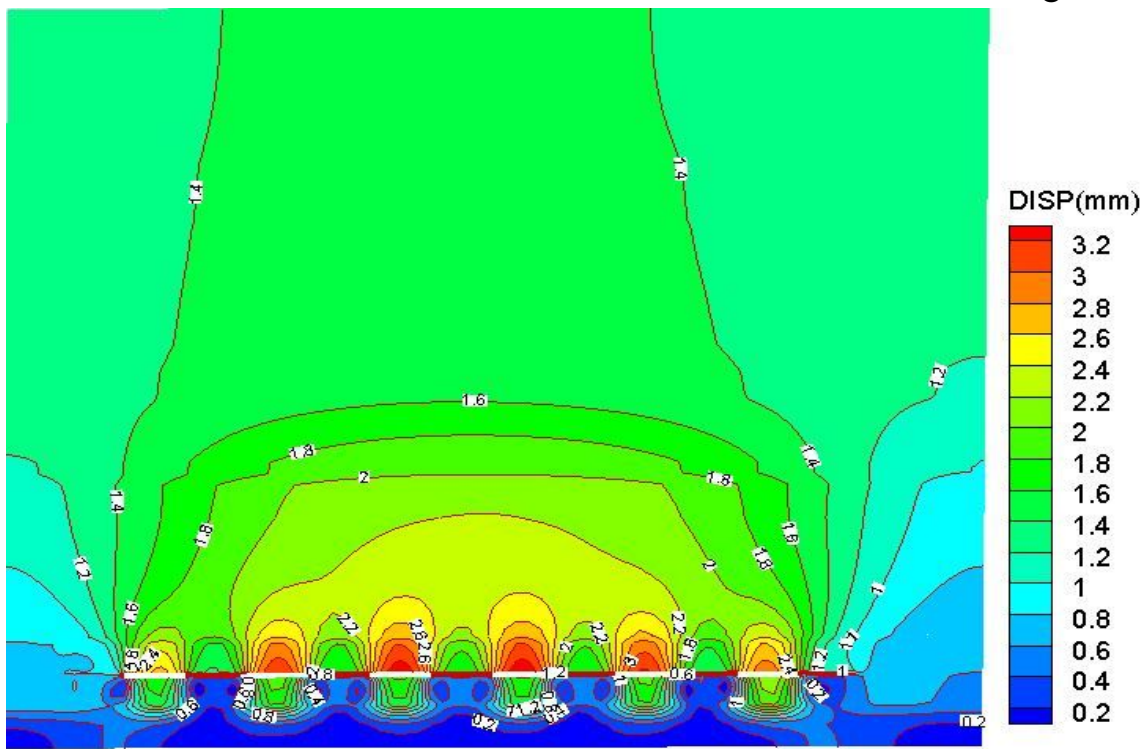

Fig. 3 Strata movement displacement contour map

From the figure 3 , there is a large arch structure in the right above mining area. But the range of arch structure is less than when filling strip width is $8 \mathrm{~m}$. At the top of mined-out area in the edge of stope, the small arch structure has a tendency to separate with the large one. In the dark green area above the filling body, the roof vertical displacement is very small, almost zero. Above strip mined-out area, roof vertical displacement is large, and each strip goaf is scattered with small arch structure whose range is less than when filling strip width is $8 \mathrm{~m}$. In the middle part of strip mined-out area, the range of arch structure is larger, and decreases from the middle part to two sides. The strip mined-out area floor has a tiny swell up and its swell up range is also arch structure, but still less than when the filling strip width is $8 \mathrm{~m}$. Comparing the simulation results comprehensively: the simulation results about three different intensity of strip filling scheme of vertical sinking are compared, as shown in the figure 4.

From the figure 4: (1) the filling strip width is different, the vertical sinking into similar basin shape, and the sinking near the middle part of mined-out area is the largest, and decreasing gradually from the center of the mining area to two sides. (2) With the increase of filling strip width, the vertical surface subsidence values decreases gradually. The greater the filling strip width, the smaller the vertical surface subsidence value, and the basin is more shallow. (3) As the filling body strength increases, the marginal effect of 
strength on vertical sinking is decreases influence of the increase of the filling progressively, that is, the greater the body strength on the surface sinking.

filling body strength, the smaller the

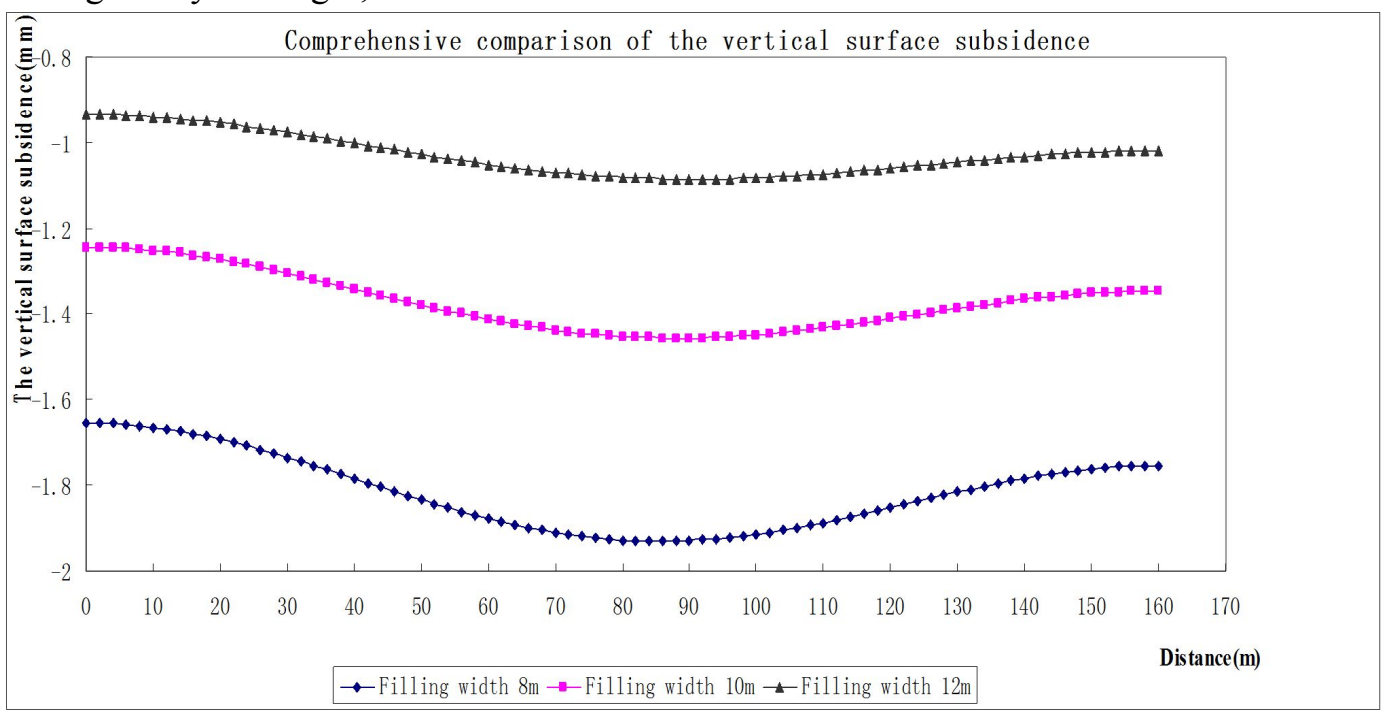

Fig. 4 Comprehensive comparison of the vertical surface subsidence

Comprehensive comparison of three

different filling widths' gradient of slope,

as shown in the figure 5.

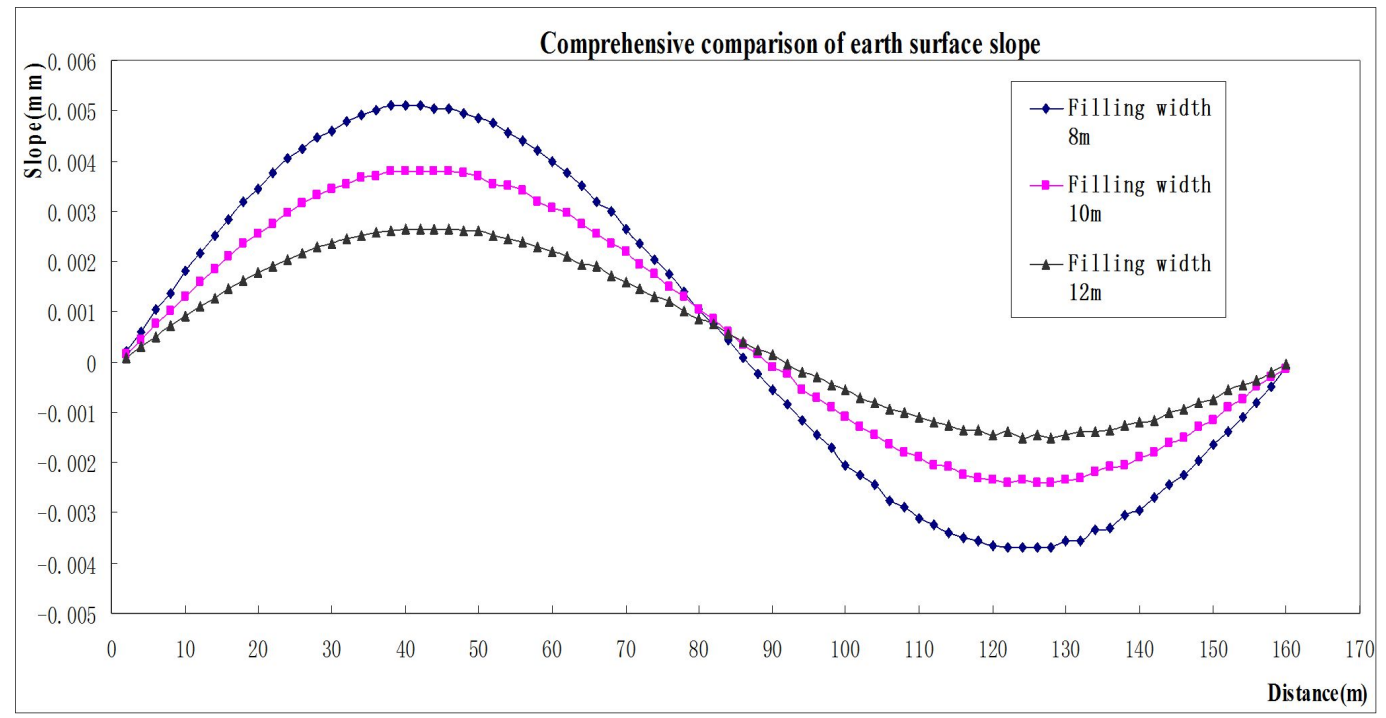

Fig. 5 Comprehensive comparison of gradient of slope

From the figure 5: (1) The filling width is different, the sine curve with the similar curve shape of gradient of slope, the sloping of the forebody of mining area is positive, and the sloping of the latter part of mining area is negative. The maximum tilt value in the first half of stope is greater than that in the second half of stope. Surface tilt has the same effect range with different incidence. (2)Three 
curves intersect at the same point, whose tilt value is zero, with each other in three positions, that is the tilt value of different filling widths in the same place is zero. (3) With the increase of filling strip width, gradient of slope (absolute value) decreases gradually, the greater the filling strip width, the smaller the gradient of slope.

Comprehensive comparison of surface curvature rule of three different filling widths, as shown in the figure 6 .

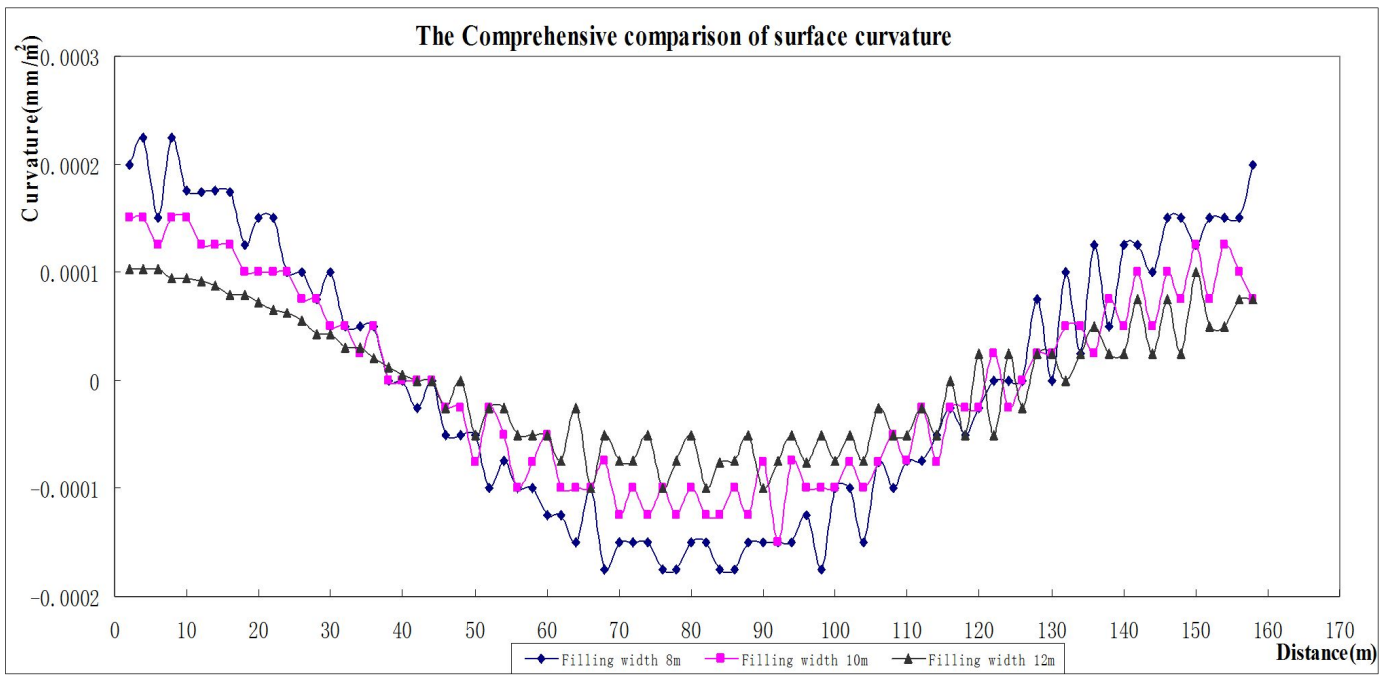

Fig. 6 Comprehensive comparison of surface curvature

From the figure 6: (1) If the filling width is different, the surface curvature curve shape is similar. The curvature is negative in the center of mining area, and the curvature at two sides is positive. (2) Both near the center of mining area and its two sides, the smaller the filling body width, the greater (absolute value) the curvature. (3) The filling body width has little effect on the surface curvature and even can be neglected.

Comprehensive comparison of surface horizontal distortion rule of three different filling widths, as shown in the figure 7 .

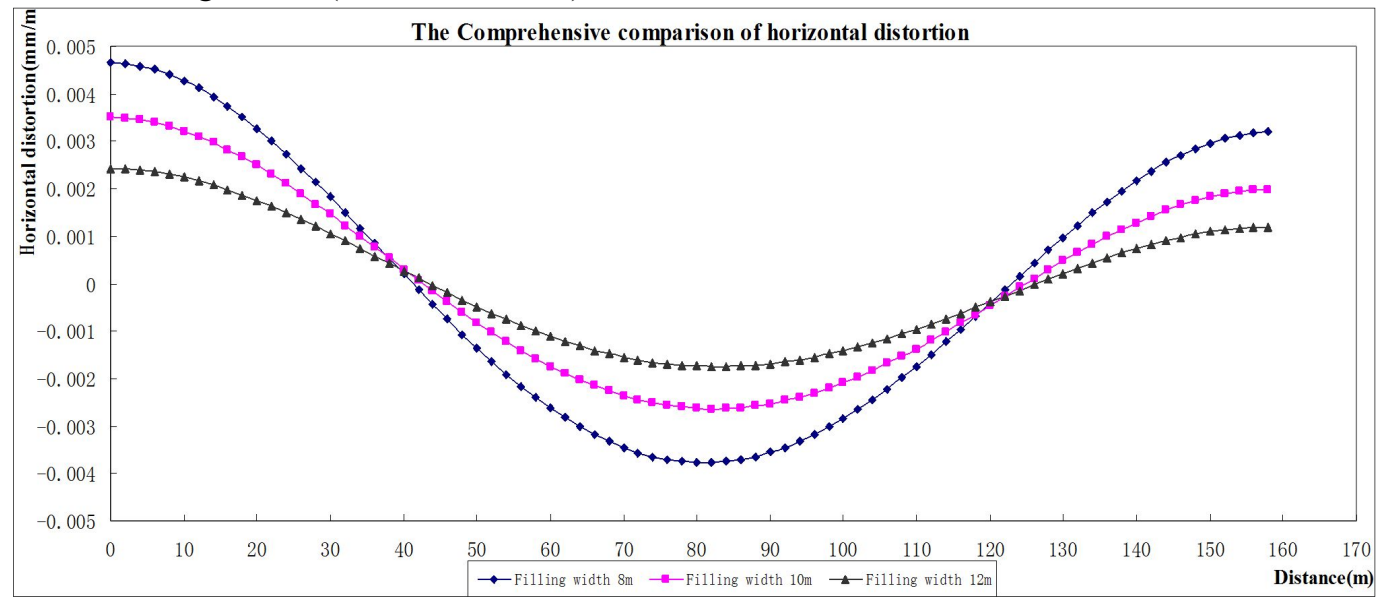

Fig. 7 Comprehensive comparison of surface horizontal distortion 
From the figure 7: (1) The filling width is different, and the surface horizontal distortion curve is the similar dissymmetric basin. Near the center of mining area, horizontal distortion is negative. In the two sides of the mining area, horizontal distortion is positive. The horizontal distortion in the first part of the stope is smaller than that in the second half. (2) Three horizontal distortion curves intersect with each other at the same point whose horizontal distortion is zero, that is, the horizontal distortion of different filling width, at the same position, is zero. (3) As the filling strip width increases, the surface horizontal distortion (absolute value) decreases gradually, the greater the filling strip width, the smaller the surface horizontal distortion.

\subsection{The effect of the filling body width}

Assume that the filling body width is $10 \mathrm{~m}$, the filling strip space is $10 \mathrm{~m}$, the numerical simulations for the filling strip strength $(8 \mathrm{MPa}, \quad 10 \mathrm{MPa}, \quad 12 \mathrm{MPa})$ respectively are analyzed. Comprehensive comparison of comprehensive vertical sinking simulation result, gradient of slope simulation result, surface curvature simulation result, surface horizontal distortion simulation result in three different strength of strip filling plans is shown in the figure $8 \sim 11$.

By analyzing the figure $8 \sim 11$ comprehensively, the results are shown in the table 2.

From the table 2, (1) According to the simulation, when the filling body width is $8 \mathrm{MPa}, 10 \mathrm{MPa}, 12 \mathrm{MPa}$ progressively, surface subsidence rule is both less than national standard, which shows that strip filling can achieve the aim to control surface subsidence. (2) With the increase of filling body strength, surface subsidence has a tendency to decreases gradually. (3) The influence of filling body strength on surface subsidence is marginal decreasing progressively.

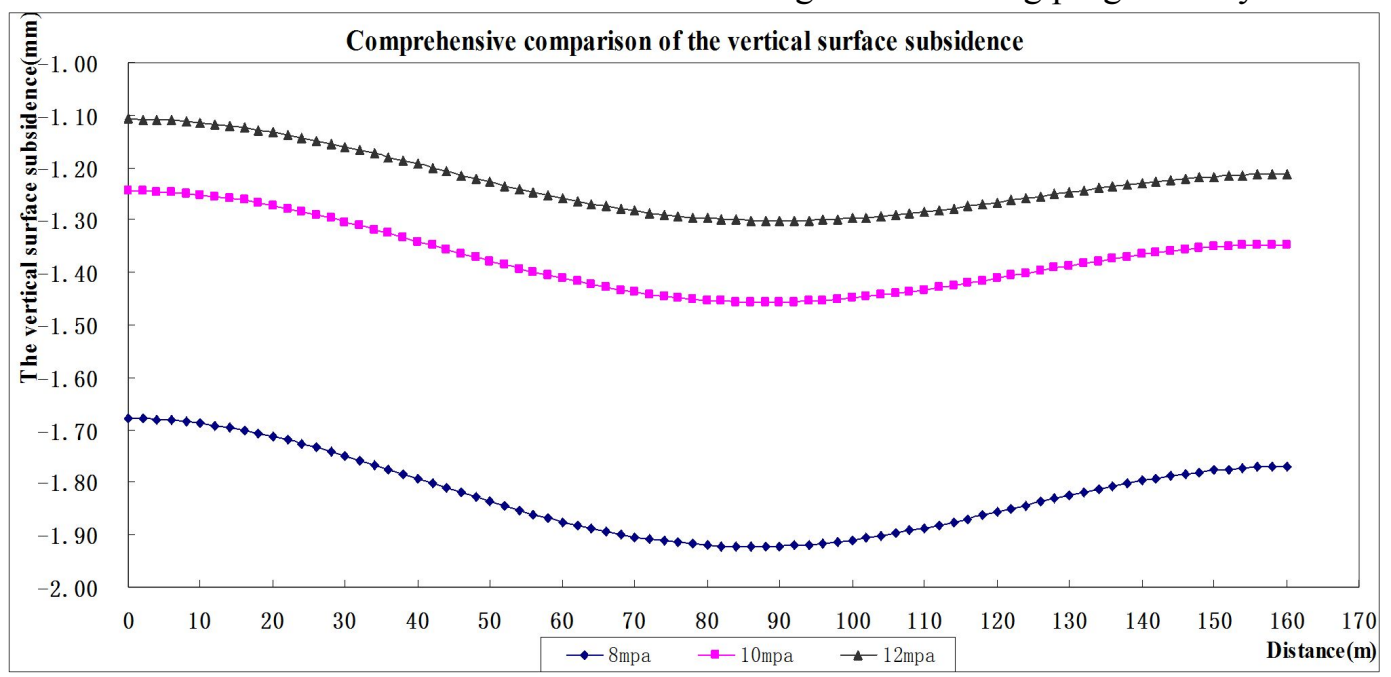

Fig. 8 Comprehensive comparison of vertical surface subsidence 


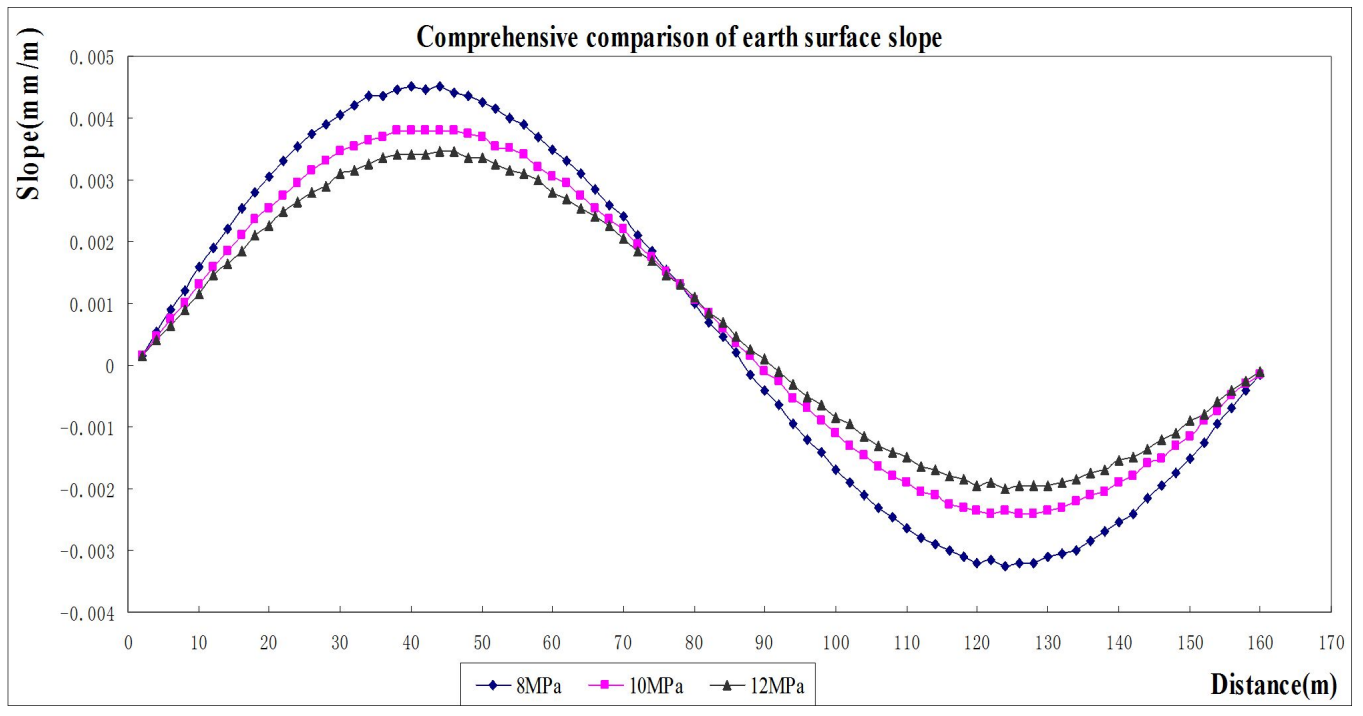

Fig. 9 Comprehensive comparison of gradient of slope

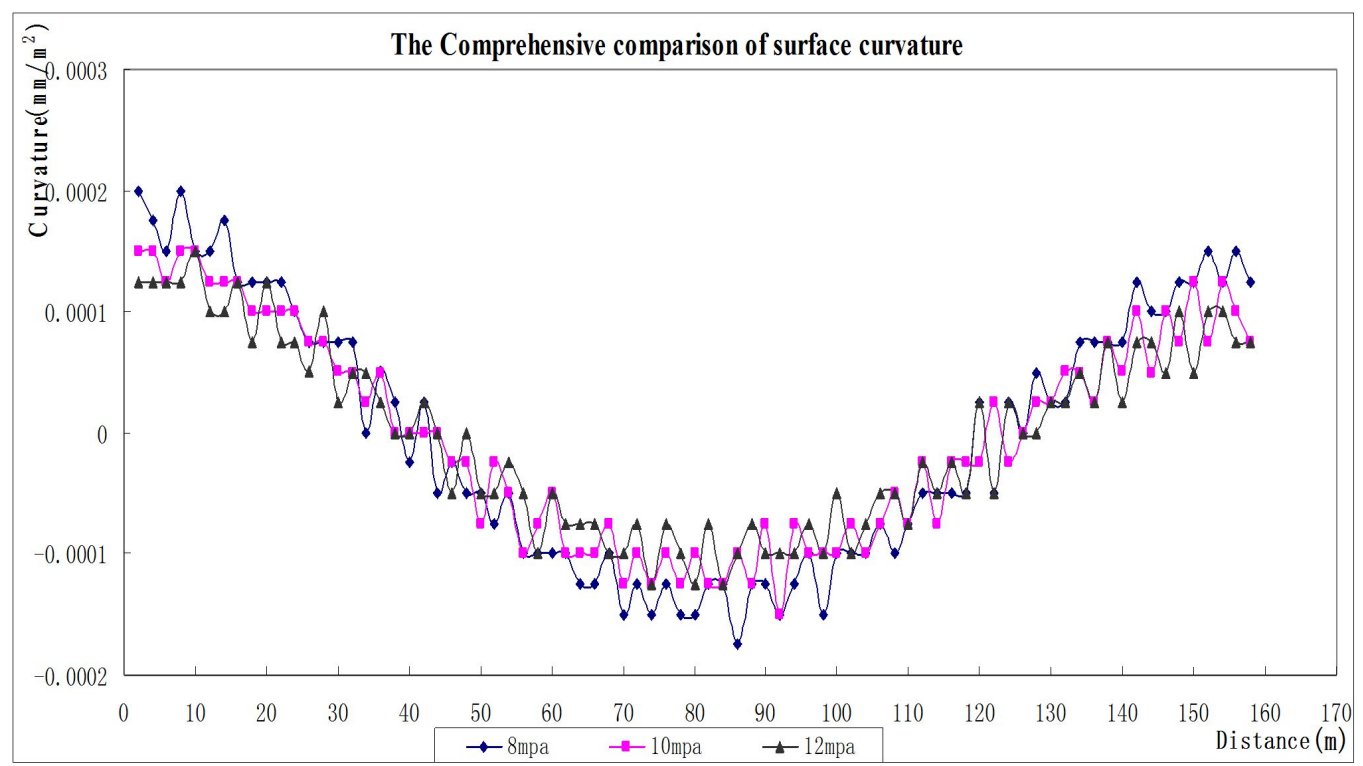

Fig. 10 Comprehensive comparison of surface curvature 


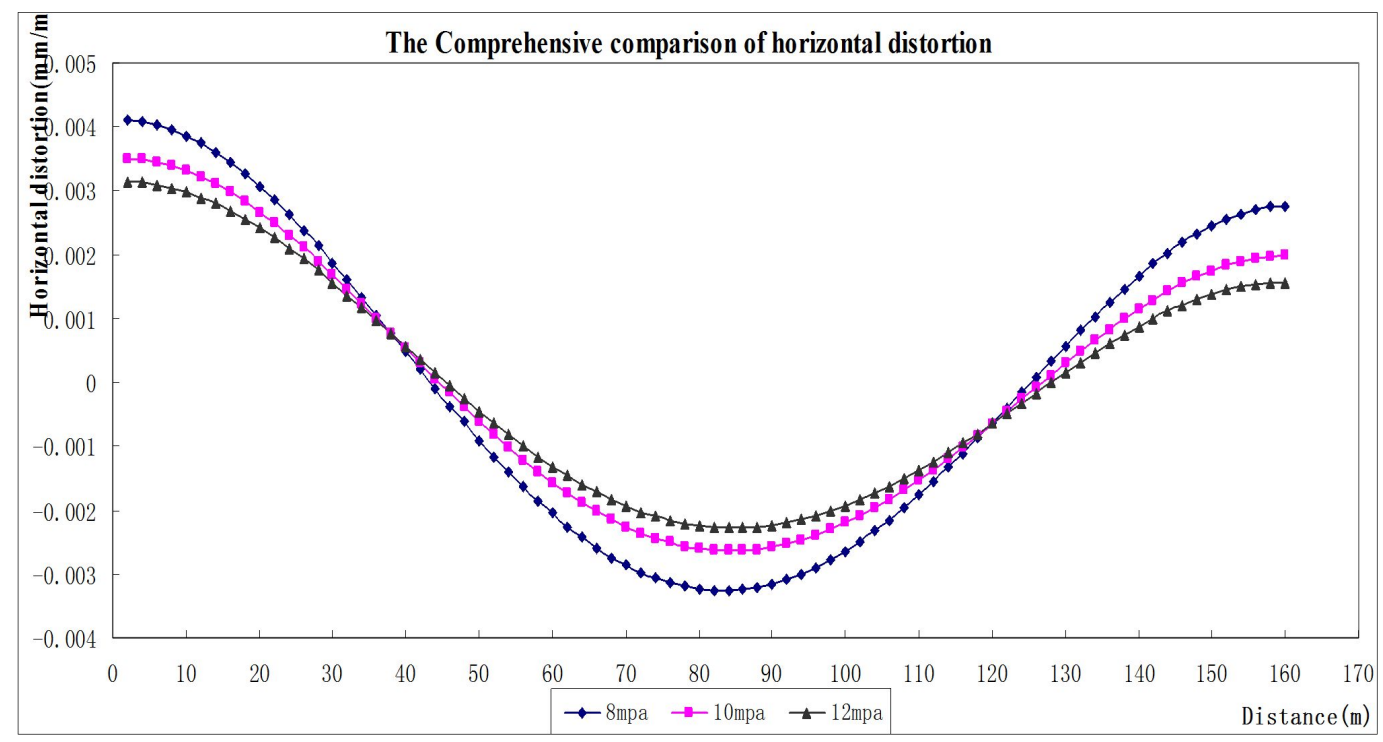

Fig. 11 Comprehensive comparison of surface horizontal distortion

Table2 The analysis result of the influence of the filling body strength factors

\begin{tabular}{|c|c|c|c|c|}
\hline $\begin{array}{c}\text { Filling Strip } \\
\text { Width }\end{array}$ & $\begin{array}{c}\text { The amount of } \\
\text { vertical } \\
\text { subsidence } \\
(\mathrm{mm})\end{array}$ & $\begin{array}{c}\text { The tilt value } \\
\text { of surface } \\
\text { lever } \\
(\mathrm{mm} / \mathrm{m})\end{array}$ & $\begin{array}{c}\text { Curvature } \\
\text { value } \\
\left(\mathrm{mm} / \mathrm{m}^{2}\right)\end{array}$ & $\begin{array}{c}\text { The deformation } \\
\text { value of surface lever } \\
\left(\mathrm{mm} / \mathrm{m}^{2}\right)\end{array}$ \\
\hline $8 \mathrm{MPa}$ & 1.93 & 0.0045 & 0.0002 & 0.0041 \\
\hline $10 \mathrm{MPa}$ & 1.46 & 0.0038 & 0.0015 & 0.0035 \\
\hline $12 \mathrm{MPa}$ & 1.32 & 0.0036 & 0.0015 & 0.0031 \\
\hline $\begin{array}{c}\text { National } \\
\text { Standards }\end{array}$ & - & 3 & 3 & 2 \\
\hline
\end{tabular}

\section{Conclusions}

A principle of strip filling controlling surface subsidence is to use the supporting of strip filling to the overburden strata in order to control the movement of the stratum. The strip filling body serves as "bridge pier" in the strip filling. The analysis shows that surface subsidence rule has close relation with the filling parameter, mainly concluding filling strip width and filling body strength, and by controlling related filling parameter to achieve the purpose of controlling surface subsidence. Designing filling parameter rationally can totally keep bridge pier structure stable. Through using FLAC3D, the effect of filling strip width and its strength on surface subsidence rule is analyzed deeply. With the increase of filling strip width, surface vertical sinking, horizontal distortion (absolute value), gradient of slope, curvature decreases gradually. As filling strip strength increases, surface vertical subsidence, horizontal distortion (absolute value), gradient of slope, curvature decreases progressively. As filling body strength increases, the effect of strength on surface vertical subsidence, horizontal distortion (absolute value), gradient of slope, curvature is marginal decreasing progressively, that is, the greater the filling body strength, the smaller the effect of the increase of filling 
body strength on surface horizontal distortion.

The analysis shows that surface distortion (the maximum sinking, curvature, horizontal distortion) can meet the requirement of protecting buildings by controlling some related filling parameter.

\section{Reference}

[1] Liu Tongyou. Filling mining technology and application [M].Beijing: Metallurgical Industry Press, 2001:272.

[2] Xu Jialin, Zhu Weibing, Li Xingshang, Lai Wenqi. Study of the Technology of Partial-Filling to Control Coal Mining Subsidence[J]. Journal of mining \& safety Engineering,2006,23(1):6-11.

[3] Zhang Huaxing, Guo Aiguo.Research on surface subsidence influential factors of wide strip filling the whole pillar mining[J].Coal Enterprise Manageme nt,2006(6):56-57. (in Chinese)

[4]Ge Haibin, Chen Shijun, Li Changhua. Research and application of strip coal pillar recovery technology under towns[C]. Strategic emerging industries and technology support, the association for science and technology academic essays of Shandong province in 2012. (in Chinese)

[5] Liu Kang, Xuan Da-yang. Comparative of Subsidence Control

Effect on Longwall Complete Filling and Strip Filling Mining[J]. Safety in Coal Mines, 2013, 44(11): 60-64.

[6] HAO Jian, SHI Yong-kui. Study on technology of on replacing strip coal pillars by strip-filling mining [J].Journal of Hunan University of Science \& Technology (Natural Science Edition), 2013, 28(2):113-116
[7] Qian Minggao, Miao Xiexing, Xu Jialin. Key Strata Theory of Strata control [M]. China University of Mining and Technology press, 2003. (in Chinese) [8] Sandra Muckelston. STRIP-MINING RECLAMATION REQUIREMENTS IN MONTANA- A CRITIQUE[J].Montana Law Review, Vol. 32 [2014], Iss.1, Art. 4.

[9] Bingnan Hu. Study on Strata Movement Control of Twice Strip Mining[CA]. Advanced Materials Research, Vols. 962-965 (2014) pp 1085-1090. 